\title{
The Photocatalytic Activity of $\mathrm{TiO}_{2}$-Zeolite Composite for Degradation of Dye Using Synthetic UV and Jeddah Sunlight
}

\author{
Laila M. Al-Harbi, ${ }^{1}$ Samia A. Kosa, ${ }^{1}$ Islam H. Abd El Maksod, ${ }^{1,2}$ and Eman Z. Hegazy ${ }^{1,2}$ \\ ${ }^{1}$ Chemistry Department, King Abdulaziz University, P.O. Box 42805, Jeddah 21551, Saudi Arabia \\ ${ }^{2}$ Physical Chemistry Department, National Research Centre, Cairo, Egypt \\ Correspondence should be addressed to Eman Z. Hegazy; ehegazy77@yahoo.com
}

Received 13 August 2014; Revised 10 October 2014; Accepted 15 October 2014

Academic Editor: Shijun Liao

Copyright (c) 2015 Laila M. Al-Harbi et al. This is an open access article distributed under the Creative Commons Attribution License, which permits unrestricted use, distribution, and reproduction in any medium, provided the original work is properly cited.

In this research different composites of impregnated $\mathrm{TiO}_{2}$ with LTA or FAU zeolites were used as different weight\% ratio for photodegradation of organic dye. Normal laboratory UV-lamps were used as a source of UV irradiation. In addition a setup of system of mirrors was used to collect real Jeddah sunlight. A comparison of UV and real sunlight photodegradation activity showed that the real sunlight enhances new centers of active sites exhibiting higher catalytic activity than that of UV irradiated samples.

\section{Introduction}

Decomposition of organic pollutants photocatalytically in the presence of $\mathrm{TiO}_{2}$ appears as a sustainable decontamination process of common application, as gas or liquid $[1,2]$. The ultraviolet (UV) energy/excitation source becomes the most practical applications due to the fact that the absorption edge of anatase $\mathrm{TiO}_{2}$ is about $380 \mathrm{~nm}$. The most solar radiation intensity reaching the earth surface is in the visible range. Systems with visible-light as an active radiation have become a priority for developing the upcoming generation of photocatalytic materials.

The composite of $\mathrm{TiO}_{2}$ fine particles with other supports such as active carbon has been proved to exhibit efficient photocatalytic reactivity [3-5]. However, black active carbon inhibits the incident UV-vis radiation to excite semiconductor photocatalysts. In comparison, $\mathrm{TiO}_{2}$ supported on transparent constituents in UV-vis regions, such as porous materials [6-10] or clays [11], has also been conveyed to show greater photocatalytic reactivity than sole $\mathrm{TiO}_{2}$. Moreover, $\mathrm{TiO}_{2}$ particles loaded on ZSM-5 zeolite [12] as well as $\mathrm{TiO}_{2}$ powders mechanically grinded with MOR zeolite [13] were proved for efficient removal of highly volatile acetaldehyde.
In addition, $\mathrm{TiO}_{2} /$ Y-zeolite hybrid photocatalysts [14] were used efficiently for removal of toluene or benzene molecules.

The above behavior could be explained by the fact that the zeolitic material adsorbs the organic compounds and easily supplies them onto the $\mathrm{TiO}_{2}$ photocatalyst surface. Another advantage of zeolite- $\mathrm{TiO}_{2}$ composite is that the adsorption capacity of the pure $\mathrm{TiO}_{2}$ sample rapidly deteriorated, while the $\mathrm{TiO}_{2}$ /zeolite hybrid system maintained a high adsorption efficiency to remove such aromatic compounds for a long period [14]. In this research, we will study the effect of different composites of $\mathrm{TiO}_{2}$-zeolite, namely, LTA and FAU materials, on the photocatalytic decomposing of organic dye using UV irradiation. In addition a developing system using direct sunlight was also used as a future system for photocatalytic decomposition of such systems.

\section{Experimental}

2.1. Materials Used. Materials used were titanium isopropoxide (Merck), LTA, FAU zeolites (synthesized from kaolin by hydrothermal treatment with $\mathrm{NaOH}$ ), LTA zeolite chemical structure being $\mathrm{Na}_{12} \mathrm{Al}_{12} \mathrm{Si}_{12} \mathrm{O}_{48} \cdot 37 \mathrm{H}_{2} \mathrm{O}$ with pore size of $4.5 \AA$, FAU chemical structure being 


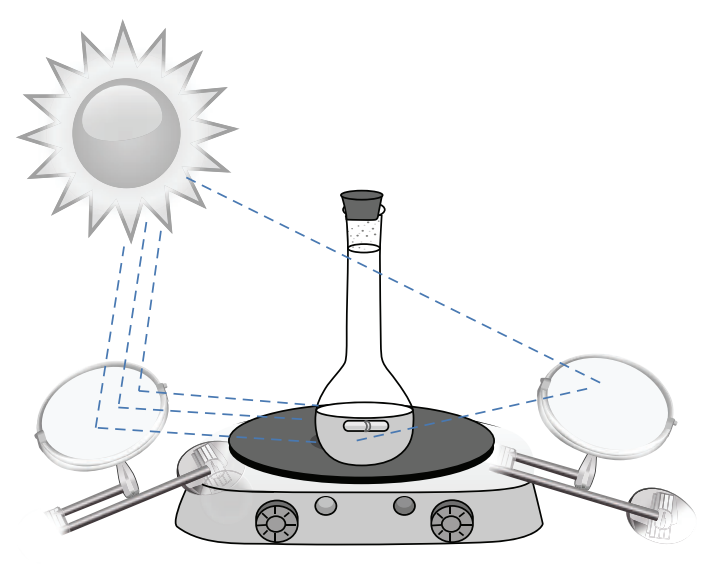

SCHeme 1: The direct sunlight reactor.

$\mathrm{Na}_{86} \mathrm{Al}_{86} \mathrm{Si}_{94.6} \mathrm{O}_{361} \cdot 228 \cdot 5 \mathrm{H}_{2} \mathrm{O}$ with pore size diameter of $7.5 \AA$, and methyl orange (Merck).

2.2. Synthesis. Titanium isopropoxide was loaded by different wt $\%$ composition on LTA or FAU, namely, 20, 50, and $70 \mathrm{wt} \%$, after which calcination at $550^{\circ} \mathrm{C}$ was performed.

\subsection{Characterization Techniques}

2.3.1. Photocatalytic Decomposition. A $100 \mathrm{~mL}$ of $500 \mathrm{ppm}$ solution of methyl orange was mixed with $0.5 \mathrm{~g}$ of composite using a horizontal cylinder annular batch reactor. A xenon lamp $(300 \mathrm{~W})$, covered by a UV filter, was used for irradiation of the photocatalyst. The photocatalytic reaction was carried out at room temperature.

The direct sunlight reactor shown in schematic diagram 1 was used using the same previous concentration of dye and same amount of the catalyst (Scheme 1).

2.3.2. XRD (X-Ray Diffraction Analysis). X-ray diffractograms of various solids were collected using a Bruker D8 advance instrument with $\mathrm{CuK} \alpha 1$ target with secondly monochromator $40 \mathrm{kV}, 40 \mathrm{~mA}$. Crystal lattice and space group analysis were performed using PhilpsX'Pert Plus V. 1.0 23. 04.1999.

2.3.3. SEM and EDX Analysis. SEM images combined with EDX analysis were taken using instrument and EDX analysis was performed using instrument "JXA-840 A electron probe microanalyzer, Japan".

2.3.4. UV Visible Spectrophotometer. The decomposition of organic dye followed using UV spectrophotometer.

2.3.5. HPLC. Some selected samples were reanalyzed by HPLC system and nearly the same results of UV were obtained. Visible spectrophotometer was attained.

The HPLC system used consisted of an Alliance Waters separations module 2695, waters 2996 photodiode array detector, and Waters 2475 multi $\lambda$ fluorescence detector (Milford, MA, USA). HPLC system control and data processing were performed by Empower software (Build 1154, Waters). Screw capped V-shaped vials, $300 \mu \mathrm{L}$, with PTFE liners were used (Alltech, GmbH, Unterhaching, Germany). Heating oven (Heraeus, Kendro, Hanau, Germany) was adjusted at $60^{\circ} \mathrm{C}$. Calibrated digital microtransfer pipettes, $5-250 \mu \mathrm{L}$, Brand, Wertheim, Germany, were used.

\section{Results and Discussion}

3.1. XRD. The XRD diffraction patterns showed that at high loading of $\mathrm{TiO}_{2}(70 \%)$ only anatase phase is showed with no trace of zeolite matrix for both LTA and FAU zeolite. For low loading, in case of FAU, also only anatase phase is observed with very low trace of FAU zeolite. In contrast at low loading (20\%) over LTA only zeolite matrix was observed with no trace of anatase phase.

The crystal lattice analysis (Table 1 ) showed that in case of $20 \% \mathrm{TiO}_{2} /$ LTA the lattice parameters slightly decreased meaning that the disappearance of anatase phase is accompanied by dissolving the $\mathrm{TiO}_{2}$ into the LTA zeolite substituting the framework [15]. In other words the change in lattice parameters of $\mathrm{TiO}_{2}$ loaded sample compared with pure LTA zeolite, $a=12.28$ (pure LTA) to $a=12.23\left(20 \% \mathrm{TiO}_{2} / \mathrm{LTA}\right)$, gives indication that the $\mathrm{TiO}_{2}$ was incorporated into the framework of zeolite.

3.2. SEM and EDX. Figures 1 and 2 showed the SEM images of different loaded samples. The images showed that in case of high loaded samples only $\mathrm{TiO}_{2}$ agglomerate matrix was observed while for low loaded samples small agglomerate of $\mathrm{TiO}_{2}$ is dispersed over an observable zeolite matrix. The EDX analysis was manipulated in Tables 2 and 3. From this table it is clearly observed that at $20 \% \mathrm{TiO}_{2} / \mathrm{LTA}$ zeolite the surface $\mathrm{TiO}_{2}$ observed by EDX analysis is much lower than those corresponding to $20 \% \mathrm{TiO}_{2} / \mathrm{FAU}$ which supports the previous XRD analysis data that the $\mathrm{TiO}_{2}$ is incorporated inside the framework of LTA zeolite. 


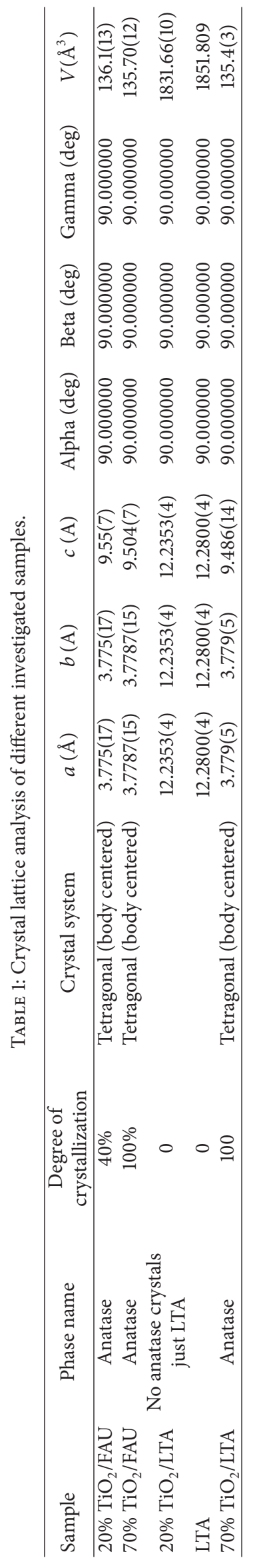



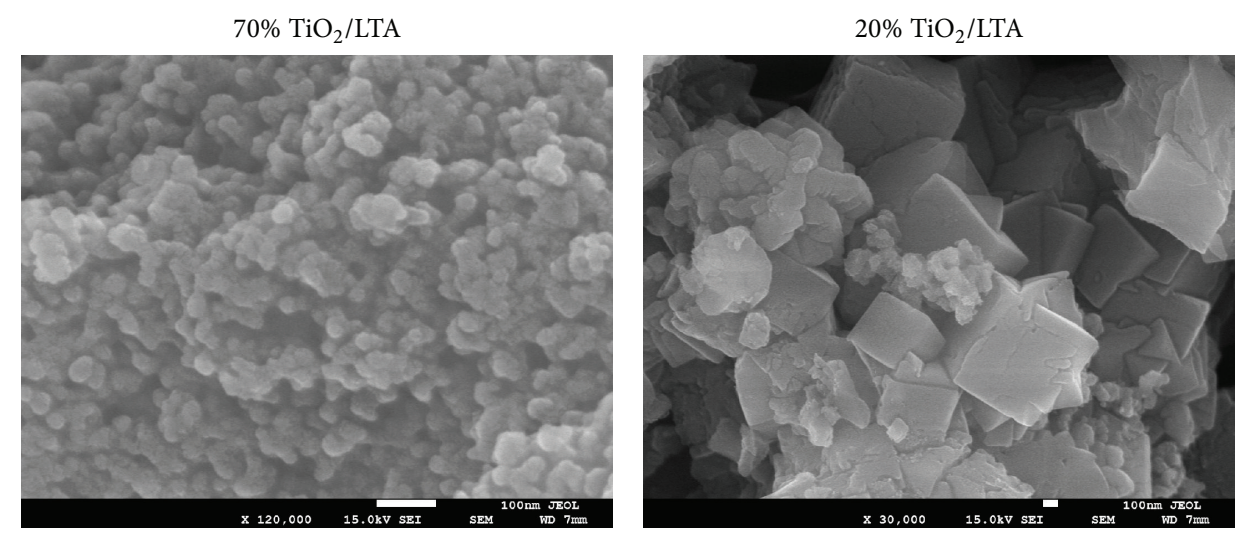

FIGURE 1: SEM of 20 and $70 \%$ loaded $\mathrm{TiO}_{2}$ on LTA zeolite.
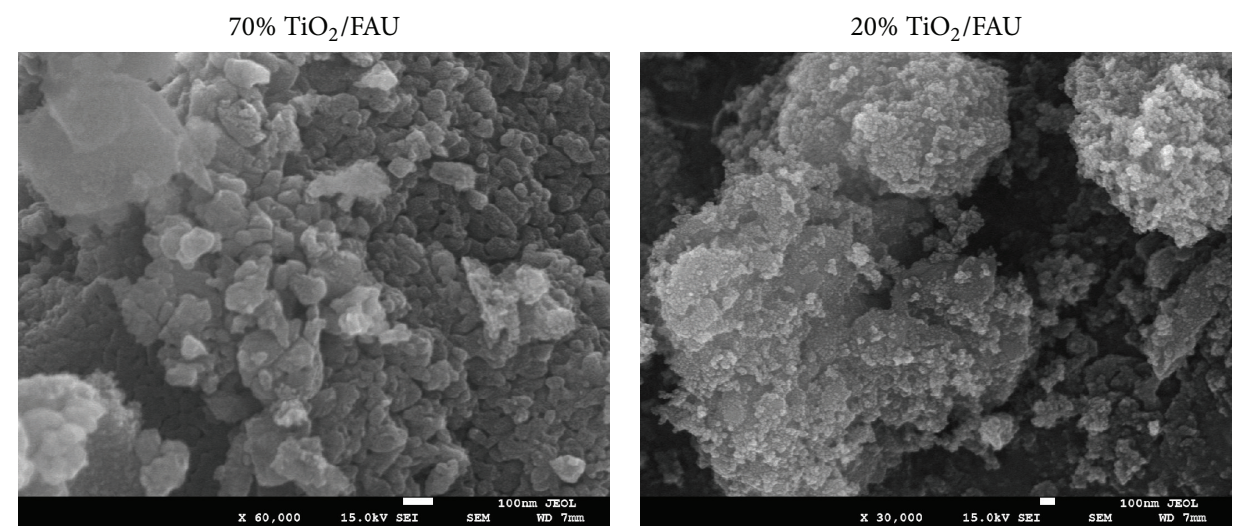

Figure 2: SEM of 20 and 70\% loaded $\mathrm{TiO}_{2}$ on LTA zeolite.

TABLE 2: Elemental EDX analysis of different catalyst samples.

\begin{tabular}{lcccc}
\hline Sample & $20 \% \mathrm{TiO}_{2} / \mathrm{X}$ & $70 \% \mathrm{TiO}_{2} / \mathrm{X}$ & $20 \% \mathrm{TiO}_{2} / \mathrm{A}$ & $70 \% \mathrm{TiO}_{2} / \mathrm{A}$ \\
\hline \multicolumn{5}{c}{$\mathrm{wt} \%$} \\
$\mathrm{O}$ & 47.49 & 47.17 & 42.93 & 46.86 \\
$\mathrm{Na}$ & 4.59 & 1.60 & 11.51 & 0.86 \\
$\mathrm{Al}$ & 9.35 & 1.09 & 18.75 & 1.12 \\
$\mathrm{Si}$ & 18.11 & 2.14 & 25.41 & 3.91 \\
$\mathrm{Ti}$ & 20.45 & 48.00 & 1.40 & 47.25 \\
\hline
\end{tabular}

TABLE 3: Oxide \% EDX analysis of different catalyst samples.

\begin{tabular}{lcccc}
\hline Sample & $20 \% \mathrm{TiO}_{2} / \mathrm{X}$ & $70 \% \mathrm{TiO}_{2} / \mathrm{X}$ & $20 \% \mathrm{TiO}_{2} / \mathrm{A}$ & $70 \% \mathrm{TiO}_{2} / \mathrm{A}$ \\
\hline \multicolumn{5}{c}{ Theoretical EDX \% of oxide } \\
$\mathrm{Na}_{2} \mathrm{O}$ & 8.75 & 3.04 & 20.17 & 1.62 \\
$\mathrm{Al}_{2} \mathrm{O}_{3}$ & 17.81 & 2.07 & 32.86 & 2.11 \\
$\mathrm{SiO}_{2}$ & 34.50 & 4.04 & 44.52 & 7.36 \\
$\mathrm{TiO}_{2}$ & 38.95 & 90.85 & 2.45 & 88.92 \\
\hline
\end{tabular}

3.3. Photocatalytic Activity. The photocatalytic activity kinetic curves of all samples (UV irradiated and sunlight irradiated) are presented in Figure 3. From this figure it could be observed that the two zeolites LTA and FAU showed two different behaviors. Thus, for UV irradiation sample loaded on FAU, the catalytic decomposition activity of 20 , $50 \% \mathrm{TiO}_{2}$ loaded samples showed nearly no catalytic activity while only $70 \%$ showed about $80 \%$ decomposition after nearly $50 \mathrm{~min}$. This could be explained that at this critical composite ratio the adsorbed dye is easily submitted to the surface of $\mathrm{TiO}_{2}$ while other ratios of loading the adsorbed dye are not transferred easily, which may be due to high adsorption power of FAU.

With sunlight irradiation, a dramatic change occurs that all catalytic activity increased meaning that there are new active sites activated only by sunlight (visible range); these active sites may be due to either some impurities in zeolite matrix or due to partial substitution of Ti into the framework of zeolite.

In contrast to FAU zeolite, LTA loaded with $\mathrm{TiO}_{2}$ showed another amazing behavior. Thus, regarding the UV irradiation, a dramatic increase of $20 \% \mathrm{TiO}_{2}$ /LTA up to $80 \%$ decomposition comparing with only $45 \%$ decomposition for both 50 and $70 \% \mathrm{TiO}_{2} /$ LTA could be explained in the light of previous XRD and SEM and EDX data that explained for this composite ratio most of $\mathrm{TiO}_{2}$ incorporated into the matrix of zeolite generating new active site to whole matrix accompanied by absence of any anatase phase of $\mathrm{TiO}_{2}$. It appeared that the catalytic activity of these new active sites is 

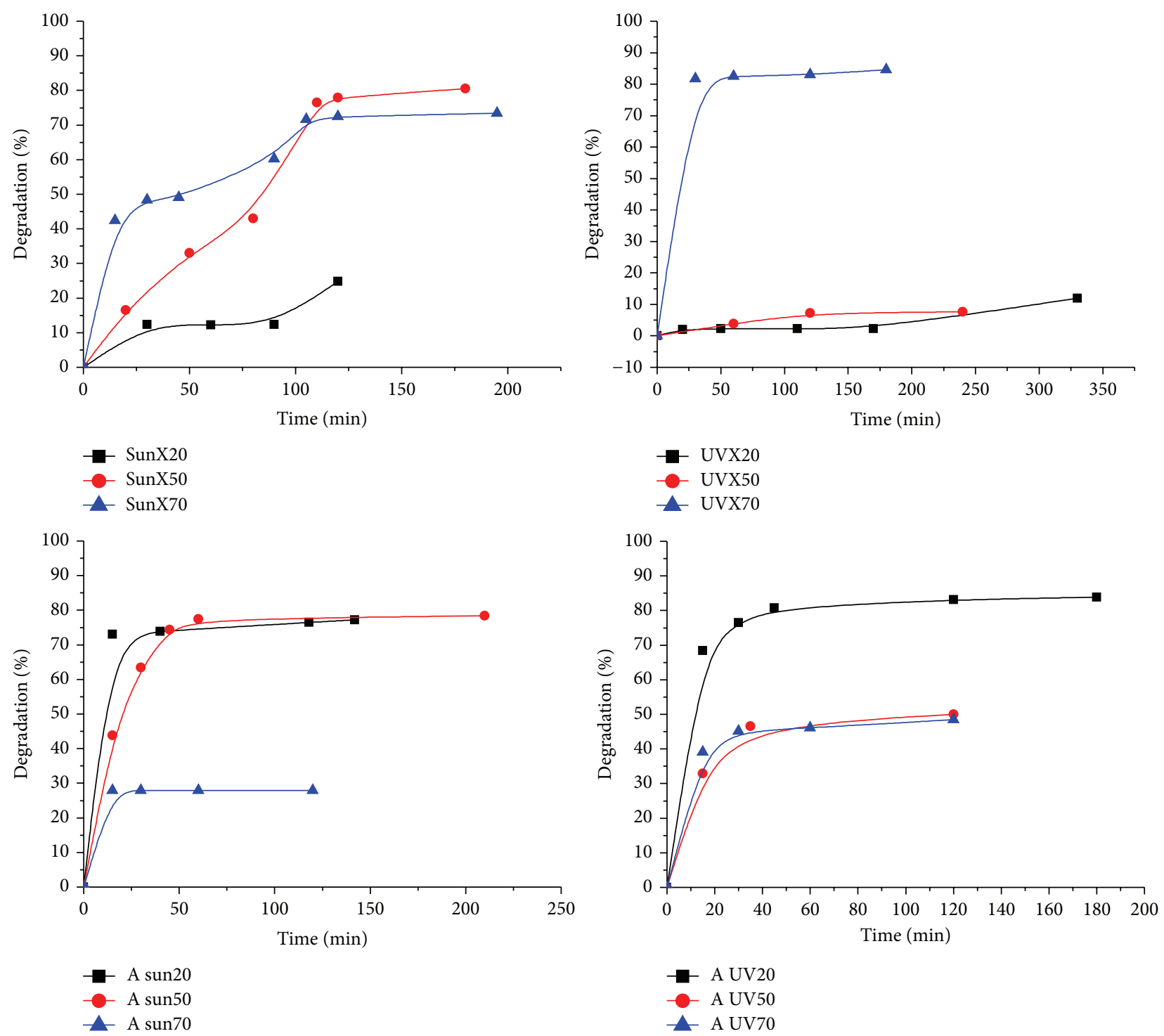

Figure 3: Photocatalytic kinetic curves of different samples under UV and direct sun irradiation.

much higher than that of even high loaded $\mathrm{TiO}_{2}$ with anatase phase detected. Studying the same system under sunlight showed that catalytic activity of $70 \% \mathrm{TiO}_{2} /$ LTA decreased than those values obtained by UV irradiation while $50 \%$ $\mathrm{TiO}_{2} /$ LTA increased dramatically under sun irradiation to be nearly the same with $20 \% \mathrm{TiO}_{2} / \mathrm{LTA}$ to be $75 \%$ decomposition. This could be explained by that the incorporated Ti into zeolite active sites is active in both sunlight and UV irradiation while at $50 \%$ loading both anatase phases with the new incorporated active site seemed to make a synergetic effect increasing dramatically the catalytic activity. However, pure anatase loaded on LTA (70\%) is less active in sunlight.

\section{Conclusions}

The following conclusions could be observed from this research.
(1) Microporous materials such as LTA and FAU could be effectively used as a good support for $\mathrm{TiO}_{2}$ photocatalyst.

(2) Loading $\mathrm{TiO}_{2}$ on these supports leads to either amorphous dispersed $\mathrm{TiO}_{2}$ or pure anatase phase of $\mathrm{TiO}_{2}$.

(3) In case of low loading of LTA (20\%) some XRD evidences for incorporation of some of titanium into the framework sites of zeolite were found.

(4) More than one evidence exists of more than one photoactive site for both UV and visible irradiations.

\section{Conflict of Interests}

The authors declare that there is no conflict of interests regarding the publication of this paper. 


\section{Acknowledgment}

This project was funded by the Deanship of Scientific Research (DSR), King Abdulaziz University, Jeddah (under Grant no. 225/247/1432). The authors, therefore, acknowledge with thanks DSR for technical and financial support.

\section{References}

[1] J.-M. Herrmann, "Heterogeneous photocatalysis: state of the art and present applications In honor of Pr. R.L. Burwell Jr. (19122003), Former Head of Ipatieff Laboratories, Northwestern University, Evanston (Ill)," Topics in Catalysis, vol. 34, no. 1-4-, pp. 49-65, 2004.

[2] M. R. Hoffmann, S. T. Martin, W. Choi, and D. W. Bahnemann, "Environmental applications of semiconductor photocatalysis," Chemical Reviews, vol. 95, no. 1, pp. 69-96, 1995.

[3] H. Yamashita, M. Harada, A. Tanii et al., "Preparation of efficient titanium oxide photocatalysts by an ionized cluster beam (ICB) method and their photocatalytic reactivities for the purification of water," Catalysis Today, vol. 63, no. 1, pp. 63-69, 2000.

[4] T. Ibusuki and K. Takeuchi, "Removal of low concentration nitrogen oxides through photoassisted heterogeneous catalysis," Journal of Molecular Catalysis, vol. 88, no. 1, pp. 93-102, 1994.

[5] H. Uchida, S. Itoh, and H. Yoneyama, "Photocatalytic decomposition of propyzamide using $\mathrm{TiO} 2$ supported on activated carbon," Chemistry Letters, vol. 22, pp. 1995-1998, 1993.

[6] N. Takeda, T. Torimoto, S. Sampath, S. Kuwabata, and H. Yoneyama, "Effect of inert supports for titanium dioxide loading on enhancement of photodecomposition rate of gaseous propionaldehyde," Journal of Physical Chemistry, vol. 99, no. 24, pp. 9986-9991, 1995.

[7] Y. Xu and C. H. Langford, "Photoactivity of titanium dioxide supported on MCM41, zeolite X, and zeolite Y," The Journal of Physical Chemistry B, vol. 101, no. 16, pp. 3115-3121, 1997.

[8] V. Durgakumari, M. Subrahmanyam, K. V. Subba Rao, A. Ratnamala, M. Noorjahan, and K. Tanaka, "An easy and efficient use of $\mathrm{TiO}_{2}$ supported HZSM-5 and $\mathrm{TiO}_{2}+\mathrm{HZSM}-5$ zeolite combinate in the photodegradation of aqueous phenol and $p$ chlorophenol," Applied Catalysis A: General, vol. 234, no. 1-2, pp. 155-165, 2002.

[9] E. P. Reddy, L. Davydov, and P. Smirniotis, “TiO ${ }_{2}$-loaded zeolites and mesoporous materials in the sonophotocatalytic decomposition of aqueous organic pollutants: the role of the support," Applied Catalysis B: Environmental, vol. 42, no. 1, pp. 1-11, 2003.

[10] J. Mo, Y. Zhang, Q. Xu, and R. Yang, "Effect of $\mathrm{TiO}_{2}$ /adsorbent hybrid photocatalysts for toluene decomposition in gas phase," Journal of Hazardous Materials, vol. 168, no. 1, pp. 276-281, 2009.

[11] C. Ooka, H. Yoshida, K. Suzuki, and T. Hattori, "Adsorption and photocatalytic degradation of toluene vapor in air on highly hydrophobic $\mathrm{TiO}_{2}$ pillared clay," Chemistry Letters, vol. 32, no. 10, pp. 896-897, 2003.

[12] M. Takeuchi, T. Kimura, M. Hidaka, D. Rakhmawaty, and M. Anpo, "Photocatalytic oxidation of acetaldehyde with oxygen on $\mathrm{TiO}_{2}$ /ZSM-5 photocatalysts: effect of hydrophobicity of zeolites," Journal of Catalysis, vol. 246, no. 2, pp. 235-240, 2007.

[13] M. Takeuchi, J. Deguchi, M. Hidaka et al., "Enhancement of the photocatalytic reactivity of $\mathrm{TiO}_{2}$ nano-particles by a simple mechanical blending with hydrophobic mordenite (MOR) zeolite," Applied Catalysis B: Environmental, vol. 89, no. 3-4, pp. 406-410, 2009.

[14] M. Takeuchi, M. Hidaka, and M. Anpo, "Efficient removal of toluene and benzene in gas phase by the $\mathrm{TiO}_{2} / \mathrm{Y}$-zeolite hybrid photocatalyst," Journal of Hazardous Materials, vol. 237-238, pp. 133-139, 2012.

[15] E. Z. Hegazy, I. H. A. El Maksod, and R. M. M. A. El Enin, "Preparation and characterization of Ti and V modified analcime from local kaolin," Applied Clay Science, vol. 49, no. 3, pp. 149-155, 2010. 

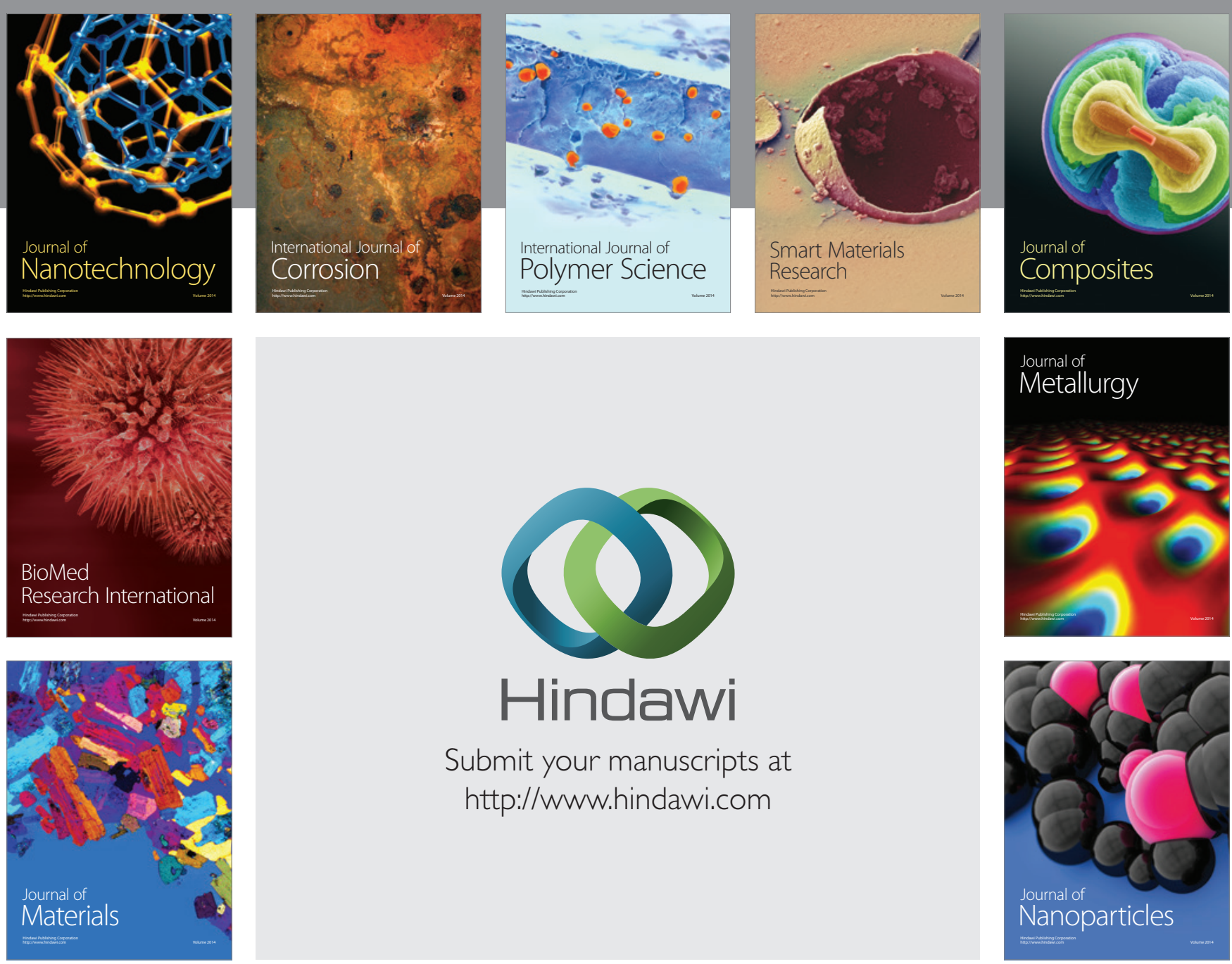

Submit your manuscripts at http://www.hindawi.com
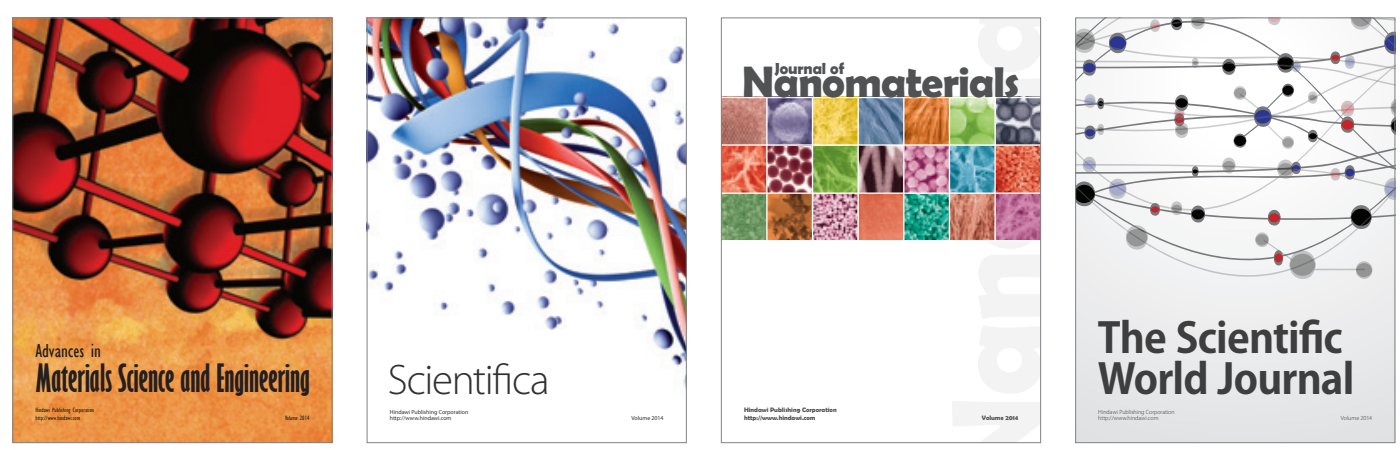

\section{The Scientific World Journal}
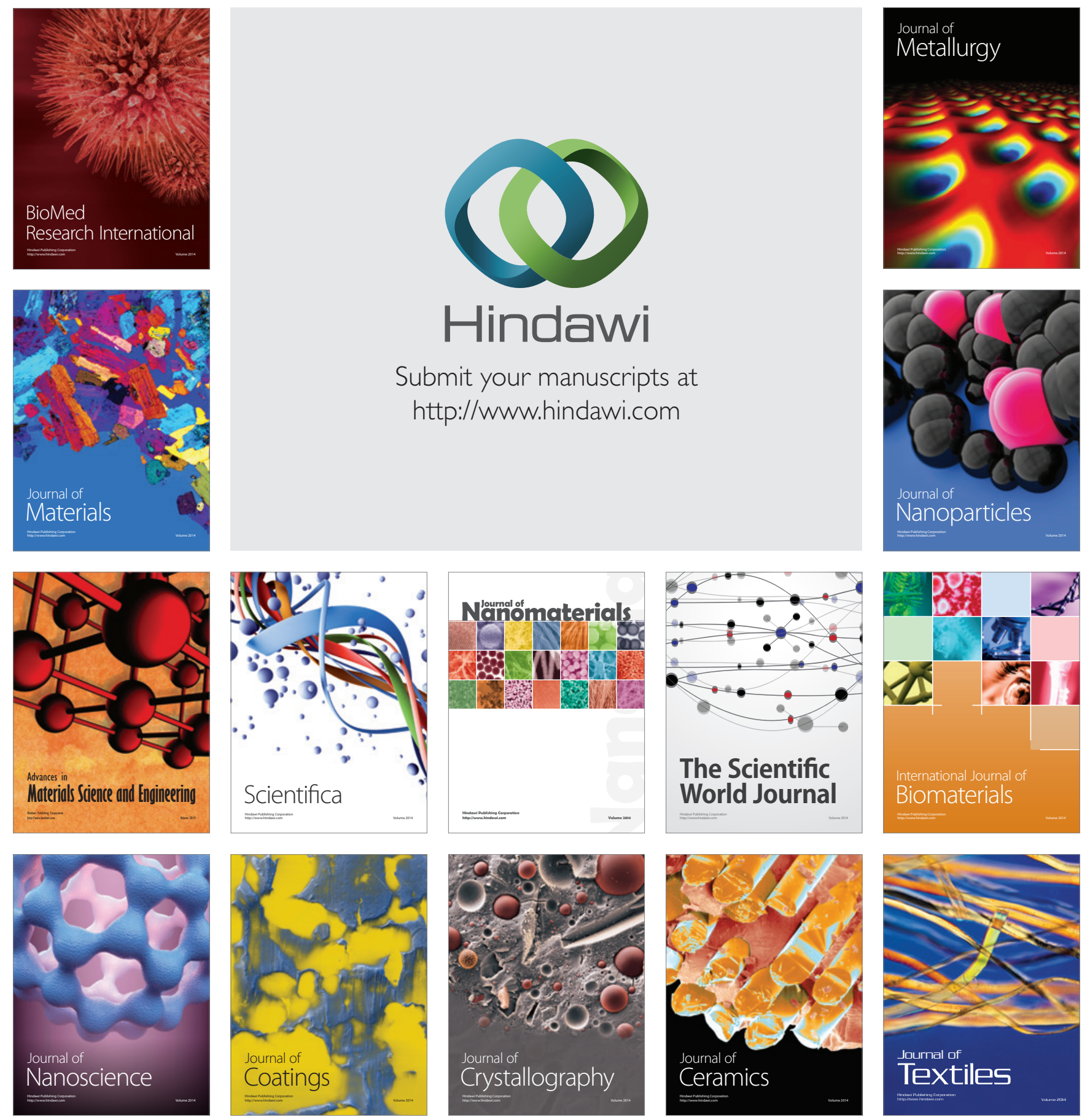